\title{
Maladaptive Perfectionism and Psychological Distress: The Mediating Role of Resilience and Trait Emotional Intelligence
}

\author{
Lily Sheppard ${ }^{1} \&$ Richard E. Hicks ${ }^{1}$ \\ ${ }^{1}$ School of Psychology, Bond University, Robina, Queensland, Australia \\ Correspondence: Lily Sheppard, Bond University, Robina, Queensland, Australia. Tel: 61-419-14-6113. E-mail: \\ lily.sheppard@student.bond.edu.au
}

Received: September 18, 2017

Accepted: October 10, 2017 Online Published: November 20, 2017

doi:10.5539/ijps.v9n4p65

URL: http://doi.org/10.5539/ijps.v9n4p65

\begin{abstract}
University students experience significantly high levels of psychological distress. Such distress has been related to depression and anxiety, which in turn have been related to low resilience and low trait emotional intelligence, and also to maladaptive perfectionism. However, no current research has investigated maladaptive perfectionism's relationship with a more general psychological distress experienced by university students. Therefore, the current study investigated associations among maladaptive perfectionism, resilience, trait emotional intelligence and psychological distress in 171 university students $\left(29\right.$ males; 138 females; $M_{\text {age }}=$ 28.48 years; $S D=11.58$ ). Results identified maladaptive perfectionism to significantly, positively correlate with psychological distress in university students. The combination of increased maladaptive perfectionism, low resilience and low trait emotional intelligence significantly predicted psychological distress. Additionally, resilience and trait emotional intelligence significantly added to the prediction of overall psychological distress, above and beyond maladaptive perfectionism. Finally, resilience and trait emotional intelligence both partially mediated the relationship between maladaptive perfectionism and psychological distress in university students. Findings suggest resilience and trait emotional intelligence to be important factors in predicting general psychological distress in student maladaptive perfectionists. The current study provided additional supporting evidence for the importance of developing resilience and trait emotional intelligence in intervention and prevention strategies for psychological distress in maladaptive perfectionist students.
\end{abstract}

Keywords: maladaptive perfectionism, psychological distress, resilience, trait emotional intelligence

\section{Introduction}

\subsection{Introduction}

Mental health issues are significant problems within academic settings, with 84 percent of university students reporting elevated levels of psychological distress (Stallman, 2010), linked to maladaptive perfectionism (Antony, Purdon, Huta, \& Swinson, 1998; Blatt, 1995; Flett, Madorsky, Hewitt, \& Heisel, 2002; Sassaroli et al., 2008). Most research has focused on maladaptive perfectionism's relationship with specific psychological disorders (Park, Heppner, \& Lee, 2010), but little research has been carried out in relation to a more general psychological distress experienced by university students (Eisenberg, Gollust, Golberstein, \& Hefer, 2007). The current study investigated a number of characteristics, including maladaptive perfectionism, that predict psychological distress in university students, or that mediate between maladaptive perfectionism and psychological distress. Identifying predictors of psychological distress and mediators between maladaptive perfectionism and psychological distress yields useful information that can be used in intervention and prevention strategies.

\subsection{Maladaptive Perfectionism and Psychological Distress}

Maladaptive perfectionism is the relentless striving for extremely high standards and critical self-evaluation of performance. It presents itself as an over concern for mistakes and setting unattainable goals (Enns \& Cox, 2012; Slaney, Rice, \& Ashby, 2002). For the current study, maladaptive perfectionism was operationally defined as Concerns for Mistakes and Doubts about Actions based on previous research and factor analysis (Frost, Heimberg, Holt, Mattia, \& Neubauer, 1993; Frost, Marten, Lahart, \& Rosenblate, 1990; Stoeber \& Otto, 2006); similar studies have also utilised these constructs to measure maladaptive Perfectionism in university students (Williams \& Cropley, 2014). 
Maladaptive perfectionism has been at the forefront of university perfectionism literature due to its associations with negative academic and psychological outcomes such as depression and anxiety disorders (Egan, Wade, \& Shafran, 2011; Stoeber \& Rambow, 2007). Previous literature has identified prevalence rates for maladaptive perfectionism to be as high as 25 percent in university students (Pirbaglou et al., 2013). University students with maladaptive perfectionism set unachievably high academic expectations and goals. Inevitable failure to achieve these goals leads the individuals to personal downgrading of their academic ability and harsh self-criticism (James, Verplanken, \& Rimes, 2015).

Maladaptive perfectionism has been associated with poor psychological outcomes in university students, such as lower levels of life satisfaction (Gnilka, Ashby, \& Noble, 2013), burnout (Chang, 2012) and eating disorders (Barnett \& Sharp, 2016; Kenny \& Hicks, 2014). There is ongoing literature supporting the relationship between psychological distress and maladaptive perfectionism. Various researchers have identified maladaptive perfectionism to be correlated with depression, anxiety and stress independently within university settings (Antony et al., 1998; Blankstein \& Lumley, 2008; Christopoulus \& Hicks, 2008; Flett et al., 2002; Hewitt, Flett, \& Ediger, 1996; Rice, Ray, David, DeBlaerer, \& Ashby, 2015).

Blankstein and Lumley (2008) investigated psychological distress symptomology and maladaptive perfectionism among 205 university students. The sample consisted of 144 females and 61 males all enrolled in an introductory psychology course (Blankstein \& Lumley, 2008). Correlational analysis again identified a significant positive relationship among multiple dimensions of psychological distress including depression and anxiety. Also, a hierarchical multiple regression identified maladaptive perfectionism to significantly predict anxiety, accounting for 25 percent of the variance in women and 35 percent of the variance in men (Blankstein \& Lumley, 2008).

Blankstein and Lumley's (2008) findings were replicated in an Australian university sample by Mead and Hicks (2010). Mead and Hicks (2010) investigated maladaptive perfectionism's relationship with depression and stress in 56 male and 159 female university students. Stress and maladaptive perfectionism, and depression and maladaptive perfectionism, were both significantly and directly correlated (Mead \& Hicks, 2010).

\subsection{Generalised Perfectionism}

Whilst there is ongoing support for maladaptive perfectionisms relationship with independent constructs of psychological distress, currently there is no research study that has investigated its relationship with a more generalised psychological distress that combined perceptions of overall stress, depression and anxiety experienced by students. Previous research also suggests that university students typically experience comorbid psychological conditions with the most common including depression and anxiety (Eisenberg et al., 2007). In order to consider the broad range of symptomology experienced by university students, the current study utilised a more general concept of psychological distress; operationally defined as the combination of depressive, anxious and stress symptomology (Henry \& Crawford, 2005; Lovibond \& Lovibond, 1995; Sinclair et al., 2012).

\subsection{Resilience}

Another variable commonly linked to psychological distress but as a buffer in university students is resilience. For the current study, resilience was operationally defined as the characteristics that enable an individual to successfully cope with and navigate adverse situations (Connor \& Davidson, 2003). The enhancing cognitive styles associated with resilience have been shown to buffer the development of depression symptoms in high stress university periods (Haefell \& Vargas, 2011). Longitudinal resilience interventions for university students have also been shown to have a positive effect on depression and anxiety; with prevalence rates starting at 27 percent and 55 percent initially and reducing to 11 percent and 31 percent respectively after a four-year period. Resilience has also been shown to be a possible mediator in the relationship between maladaptive perfectionism and psychological distress. Utilising Baron and Kenny's (1986) stepwise model, Klibert et al. (2014) identified resilience at university to partially mediate the relationship between maladaptive perfectionism and depression, and between maladaptive perfectionism and anxiety. Whilst previous literature has documented the relationship between psychological distress elements and resilience, our current study investigated whether resilience mediates the relationship between maladaptive perfectionism and generalised distress.

\subsection{Trait Emotional Intelligence}

Another buffer effecting the perfectionism-generalised distress relationship is trait emotional intelligence is a lower order personality dimension associated with emotional information processing (Petrides \& Furnham, 2001). Trait emotional intelligence was operationally defined within the current study as "a constellation of emotional self-perceptions and dispositions located at the lower levels of personality hierarchies" (Petrides, Pérez-González, \& Furnham, 2007, p. 26). Empirical evidence has previously demonstrated high trait emotional 
intelligence to be associated with improvements in academic, behaviour and psychological outcomes such as depression and cognitive affect in university students (Armstrong, Galligan, \& Critchley, 2011; Fernandez, Salamonson, \& Griffith, 2012; Petrides, Pérez-González, \& Furnham, 2007; Rice, Vergara, \& Aldea, 2006). Trait emotional intelligence significantly predicts depression's affective, cognitive and somatic symptoms (Chow, Chiu, \& Wong, 2011) and is a significant predictor of perceived stress in university students (Forushani \& Besharat, 2011). Low trait emotional intelligence has also been shown to increase the risk of developing emotional disorders such as depression and anxiety in university students (Constantin et al., 2016).

In accordance with theory and literature, individuals high in maladaptive perfectionism are likely to present with low trait emotional intelligence (Aldea \& Rice, 2006). Emotional dysregulation has been found to mediate the relationship between maladaptive perfectionism and psychological distress (Aldea \& Rice, 2006). Poor trait emotional intelligence has also been linked to higher rates of neuroticism and maladaptive perfectionism (Smith, Saklofske, \& Nordstokke, 2014). Trait emotional intelligence was shown to partially mediate the relationship between neuroticism and aspects of perfectionism, suggesting trait emotional intelligence as a potential mediator between the relationship of maladaptive perfectionism and psychological distress (Smith et al., 2014). Our research investigated trait emotional intelligence as a mediator between maladaptive perfectionism and psychological distress.

\subsection{Resilience and Trait Emotional Intelligence}

According to Armstrong et al. (2011), trait emotional intelligence and resilience may be directly related. Armstrong et al. (2011) suggested the idea that emotionally intelligent behaviours within stressful situations are considered to be adaptive and therefore resilient. Essentially, trait emotional intelligence is considered an antecedent of resilience, facilitating resilient behaviours (Magnano, Craparo, \& Paolillo, 2016). Several studies have indicated resilient behaviours to be associated with optimism, energetic approaches to life, curiosity and openness to new experiences, all of which are also characterised by positive emotionality (Block \& Kremen, 1996; Klohnen, 1996; Tugade \& Fredrickson, 2004). Additional evidence suggests that high resilient people proactively cultivate positive emotionality by strategically eliciting positive emotions through the use of humour (Werner \& Smith, 1992), relaxation techniques (Demos, 1989; Wolin S. J. \& Wolin, S., 1993) and optimistic thinking (Krumpfer, 1999). From this, it is suggested resilience and trait emotional intelligence possess similar contributions towards psychological distress, particularly in university students.

\subsection{The Current Study}

Previous literature has verified the relationship between maladaptive perfectionism and dimensions of psychological distress (e.g., Flett et al., 2002). Previous literature has also identified maladaptive perfectionism, resilience and trait emotional intelligence as significantly predicting depression and anxiety in university students (e.g., Aldea \& Rice, 2006; Haefell \& Vargas, 2011; Jackson \& Hicks, 2008; Mead \& Hicks, 2010). However, little research had investigated maladaptive perfectionism's association with a more general psychological distress typically experienced by university students (Eisenberg et al., 2007). Therefore, the current study investigated these relationships., along with investigating whether resilience and trait emotional intelligence independently act as mediators between maladaptive perfectionism and psychological distress (Klibert et al., 2014; Smith et al., 2014).

Based on the research cited above, the following hypotheses were developed:

H1: that maladaptive perfectionism and psychological distress would be significantly, positively correlated in university students.

$\mathrm{H} 2$ : that the combination of resilience (negatively), trait emotional intelligence (negatively) and maladaptive perfectionism (positively) would significantly predict psychological distress in university students.

H3: that resilience would significantly mediate the relationship between maladaptive perfectionism and psychological distress in university students.

H4: that trait emotional intelligence would significantly mediate the relationship between maladaptive perfectionism and psychological distress in university students.

\section{Method}

\subsection{Participants}

The current study consisted of 171 convenience sampled university students with 29 males (16.96\%), 138 females $(80.70 \%)$, two transgender participants $(1.17 \%)$ and two participants $(1.17 \%)$ who did not identify with a gender $\left(M_{\text {age }}=28.48, S D_{\text {age }}=11.58\right)$. See table 1 for further participant demographics. 
Table 1. Participant information

\begin{tabular}{|c|c|c|}
\hline Characteristic & $n$ & Percentage \\
\hline \multicolumn{3}{|l|}{ Type of Study } \\
\hline Part-time & 48 & 28.40 \\
\hline Full-time & 121 & 71.60 \\
\hline \multicolumn{3}{|c|}{ Highest Education } \\
\hline High School & 65 & 38.01 \\
\hline Diploma & 60 & 35.09 \\
\hline Bachelor & 30 & 17.54 \\
\hline Honours & 7 & 4.09 \\
\hline Masters & 9 & 5.26 \\
\hline \multicolumn{3}{|l|}{ Employment } \\
\hline Unemployed & 56 & 32.75 \\
\hline Casual & 53 & 30.99 \\
\hline Part-time & 37 & 21.64 \\
\hline Full-time & 25 & 14.62 \\
\hline \multicolumn{3}{|c|}{ Intimate Relationship } \\
\hline Yes & 87 & 51.18 \\
\hline No & 83 & 48.82 \\
\hline
\end{tabular}

\subsection{Materials}

2.2.1 Depression Anxiety Stress Scale-21 (DASS-21; Lovibond \& Lovibond, 1995)

The DASS-21 was used to measure general psychological distress in the sample by combining the three sub-scales of depression, anxiety and stress (Eisenberg et al., 2011). The DASS-21 is measured using a four-point Likert scale ranging from $0=$ did not apply to me at all to $3=$ applied to me very much or most of the time. Higher scores on the DASS-21 indiciate higher levels of psychological distress (Lovibond \& Lovibond, 1995). The DASS-21 was chosen due to its adequate reliability and validity (Brown, Chorpita, Korotitsch, \& Barlow, 1997; Lovibond \& Lovibond, 1995). The internal reliability of the DASS-21 has previously been found to range from .88 to .96 (Brown et al., 1997). For the current study was consistent with previous literature, with the construct showing a Cronbach's alpha of .96 (Brown et al., 1997).

\subsubsection{Frost Multidimensional Perfectionism Scale (F-MPS; Frost et al., 1990)}

The F-MPS is a 35-item self-report questionnaire designed to measure an individuals need for perfectionism on six sub-scales. The six sub-scales include Doubts About Action, Concerns Over Mistakes, Personal Standards, Parental Expectations, Parental Criticism and Organisation. The current study utilised a combined total score of the Doubts about Action and Concern over Mistake subscales to represent maladaptive perfectionism (Stoeber \& Otto, 2006). The F-MPS requires the participant to rank the level of agreement to a range of statements on a five-point Likert scale ranging from $1=$ Strongly Disagree to $5=$ Strongly Agree. Higher scores on the F-MPS factors and total scores indicate greater amounts of perfectionism. Consistent with previous literature, the current sample possessed adequate internal reliability, demonstrating a Cronbach's alpha of .92 for the total scale (Frost et al., 1993; Lynd-Stevenson \& Hearne, 1999). Independently, Doubt about Actions met a Cronbach's alpha of .78. The Concerns over Mistakes subscale reached a Cronbach's alpha of .93. The maladaptive perfectionism factor structure was verified in a confirmatory factory analysis of female undergraduate students (Powers, Zuroff, \& Topciu, 2003).

\subsubsection{Connor-Davidson Resilience Scale-25 (CD-RISC-25; Davidson \& Connor, 2016)}

The CD-RISC-25 is a self-report questionnaire that was used to measure the participants level of resilience. Participants responded on a five-point Likert scale on personal applicability to 25 statements, with reference to the previous month (Davidson \& Connor, 2016). Higher scores on the CD-RISC-25 indicate higher levels of resilience. The CD-RISC-25 has previously demonstrated adequate reliability and validity (Connor \& Davidson, 2003; Mcgahuey et al., 2000). The internal reliability of the CD-RISC-25 for the current study was consistent 
with previous literature, with a Cronbach's alpha of .91 (Connor \& Davidson, 2003. Strong negative correlations between the CD-RISC-25 and Perceived Stress Scale has previously confirmed convergent validity of the questionnaire (Connor \& Davidson, 2003; Kobasa, 1979).

\subsubsection{Trait Emotional Intelligence Questionnaire—Short (TEIQ-S; Petrides, 2009)}

The TEIQ-S is a 30-item self-report questionnaire designed to measure an individual's capacity for emotional awareness and control. It ranges on a seven-point Likert scale where participants note the level of agreement to 30 statements creating an overall global score of Trait Emotional Intelligence. Higher scores on the TEIQ-S demonstrate higher levels of trait emotional intelligence (Petrides, 2009). The TEIQ-S demonstrates adequate reliability and validity (Cooper \& Petrides, 2010; Laborde, Allen, \& Gullén, 2016). The current study identified adequate internal reliability for the TEIQ-S, with a Cronbach's alpha of .83 (Cooper \& Petrides, 2010). Construct validity of the measure has also been confirmed through factor analysis (Laborde et al., 2016).

\subsection{Procedure}

Ethical approval was obtained through two university Human Research Ethics Committees. Participants were convenience sampled and voluntarily opted to complete the questionnaire through social media avenues such as Facebook, university participant pools and direct email with gatekeeper permission. All material was completed online, in uncontrolled settings using Qualtrics as the survey software.

Participants initially read an explanatory statement in order to give informed consent and comply with ethical considerations. Participants were then shown a page of definitions regarding the difference between eustress and distress (Kent, 2006) and were informed to consider the questions based on a more negative form of stress (distress). The definitions were an ethical requirement utilised to improve construct validity of the study and reduce the likelihood of confusing stress and distress. Participants then completed the series of questionnaires involving demographic items, the DASS-21, FMP-S, CD-RISC-25 and TEIQ-S. Questionnaire responses and coded data were stored on a password-secure Network Drive folder.

\section{Results}

\subsection{Preliminary Analyses}

An alpha level of .05 was used to determine statistical significance. Statistical analyses were conducting using IBM Statistical Package for the Social Science (Version 24). The data was checked for any univariate outliers using visual inspection of box and whisker plots, which identified 11 univariate outliers. Mahalanobis Distance probability identified two multivariate outliers ( $p<.001$; Tabachnick \& Fidell, 2013). Due to the sensitivity of regression, analyses were run with and without the outliers to determine whether there was a difference in the final significant values. Removal of the outliers revealed no differences in final significance values, therefore the outliers were retained in the dataset. A small number of missing items in the TEIQ-S and the DASS-21 were replaced using mean imputation following Tebachnick and Fidell (2013).

Gender, age, employment and relationship status have previously been investigated in other studies as covariates of psychological distress and have shown inconsistent affects (Hurst, Baranik, \& Daniel, 2013; Mounsey, Vandehey, \& Diekhoff, 2013; Schewitz \& Hamilton, 2002; Sherry, Sherry, Hewit, Mushquash, \& Flett, 2015). Therefore, the current study investigated these demographic characteristics to determine their relationship with psychological distress.

One-way ANOVA's revealed no significant differences in psychological distress for gender, $F(3,162)=.66, p$ $=.60$, and employment status, $F(3,162)=1.38, p=.25$. An independent $t$-test revealed no significant difference in psychological distress levels of full-time and part-time students, $t(159)=1.62, p=.11$, and no significant difference in those in a committed relationship and those who were not, $t(160)=.74, p=.46$. Age was also found to have no significant correlation with any of the outcome or predictor variables. All correlations fell in the expected directions with maladaptive perfectionism significantly, positively correlating with psychological distress as hypothesised. Refer to Table 2 for correlations, means and standard deviations. 
Table 2. Correlations, means and standard deviations for resilience, trait emotional intelligence, maladaptive perfectionism and psychological distress $(\mathrm{N}=171)$

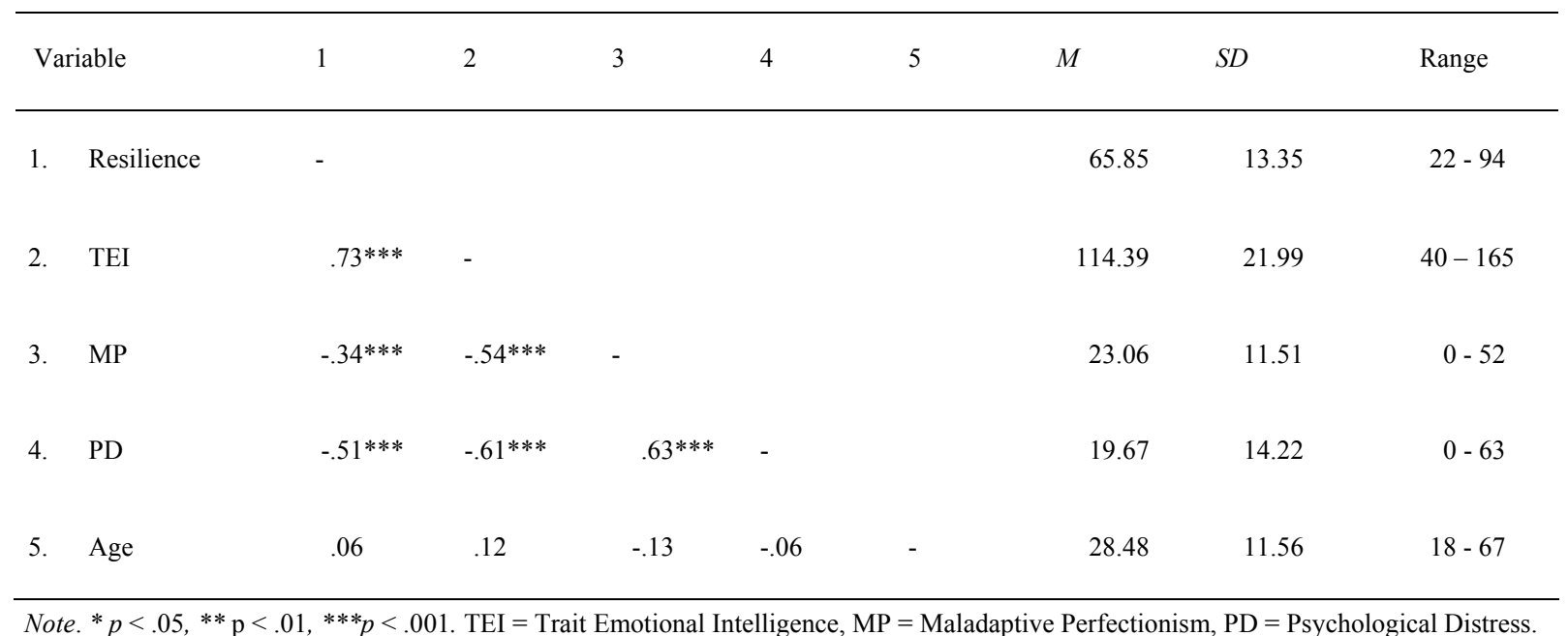

\subsection{Regression Analyses}

A hierarchical regression was used to test the predictability of maladaptive perfectionism, resilience and trait emotional intelligence on psychological distress (see Table 3). Maladaptive perfectionism was entered at step 1 with resilience and trait emotional intelligence being entered at step 2. Independently, maladaptive perfectionism had a significant effect on predicting psychological distress, $F(1,151)=86.36, p<.001$. Maladaptive perfectionism explained 36.4 percent of the variance in psychological distress. At step 2, resilience and trait emotional intelligence (negatively weighted) made a significant contribution to the prediction of psychological distress $\Delta F(2,149)=20.25, p<.001$, contributing an additional 13.6 percent of the variance in psychological distress. The total model remained significant and accounted for 50 percent of the variance in psychological distress, $F(3,149)=49.63, p<.001$.

Table 3. Variance explained, unstandardised B, standard error, standardised beta coefficient and confidence intervals for the model predicting psychological distress $(\mathrm{N}=171)$

\begin{tabular}{|c|c|c|c|c|c|c|c|}
\hline Variable & $R$ & $R^{2}$ & $\Delta R^{2}$ & $B$ & $\operatorname{SE} B$ & $\beta$ & $95 \%$ CI for $B$ \\
\hline Step 1 & .60 & .36 & & & & & \\
\hline Constant & & & & 2.41 & 2.06 & & {$[-1.87,6.49]$} \\
\hline MP & & & & $.75 * * *$ & .08 & .60 & {$[.59, .91]$} \\
\hline Step 2 & .71 & .50 & $.14 * * *$ & & & & \\
\hline Constant & & & & 40.48 & 6.51 & & {$[29.62,53.34]$} \\
\hline MP & & & & $.51 * * *$ & .09 & .37 & {$[.34, .67]$} \\
\hline Resilience & & & & $-.21 * *$ & .09 & -.21 & {$[-.39,-.04]$} \\
\hline TEI & & & & $-.16^{* *}$ & .06 & -.24 & {$[-.29,-.04]$} \\
\hline
\end{tabular}

Note. $* p<.05, * * p<.01, * * * p<.001 . \mathrm{SE}=$ standard error. $\mathrm{CI}=$ confidence interval. MP $=$ maladaptive perfectionism. TEI $=$ trait emotional intelligence.

\subsection{Mediation Analyses}

Mediation analyses were conducted using Baron and Kenny's (1986) Step-Wise Model. Initially, maladaptive perfectionism was considered a significant predictor of psychological distress $(\beta=.60, p<.001)$. Resilience was then included into the mediation analysis and the regression between maladaptive perfectionism and psychological distress dropped, however remained significant $(\beta=.50, p<.001)$. A Sobel test (Preacher, 2017) 
revealed a significant decrease in the $\beta$ of maladaptive perfectionism and psychological distress with the implementation of resilience as a mediator $(z=3.94, p<.001)$ identifying resilience as a partial mediator between maladaptive perfectionism and psychological distress (see Figure 1).

\section{Unmediated Model}

$$
\beta=.60, p<.001
$$

\section{Maladaptive Perfectionism}

\section{Psychological Distress}

\section{Mediated Model}

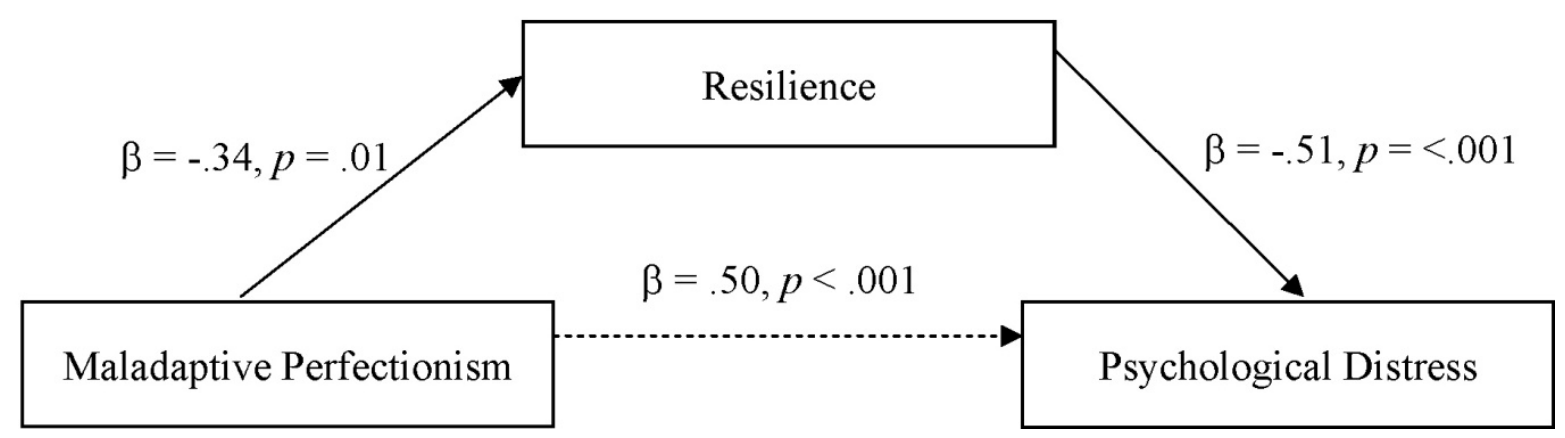

Figure 1. Direct and indirect pathways between maladaptive perfectionism, resilience and psychological distress

\section{Unmediated Model}

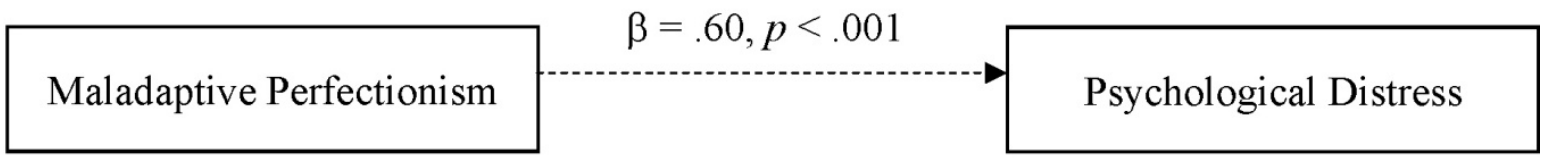

\section{Mediated Model}

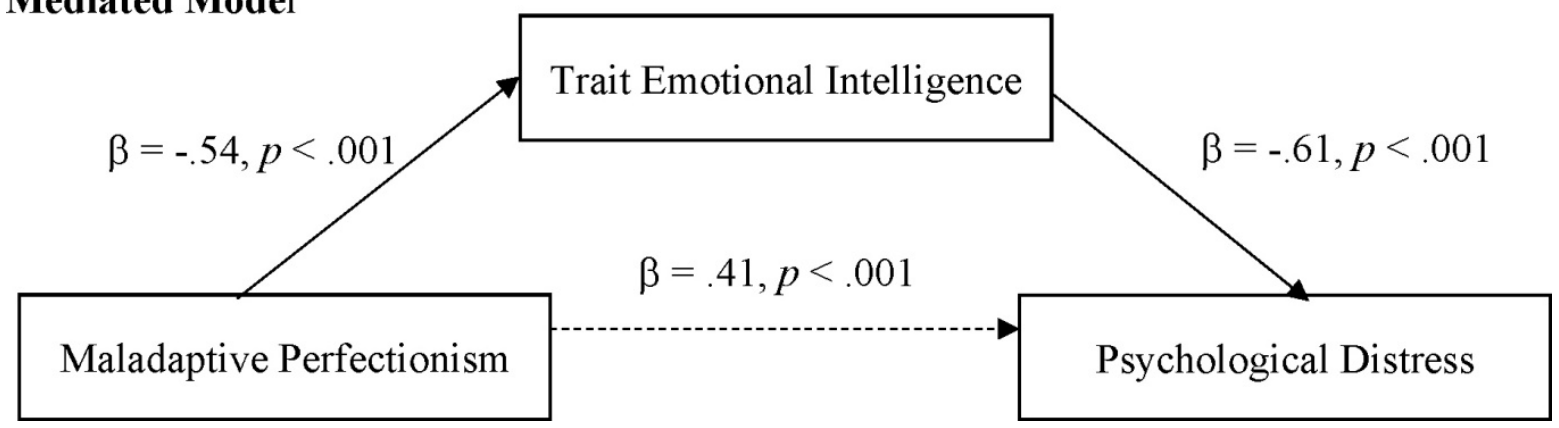

Figure 2. Direct and indirect pathways between maladaptive perfectionism, trait emotional intelligence and psychological distress

As mentioned above, maladaptive perfectionism was originally found to be a significant predictor of psychological distress $(\beta=.60, p<.001)$. Trait emotional intelligence was then included into the model, and the regression dropped to $\beta=.41$, however remained significant $(p<.001)$. A Sobel test (Preacher, 2017) also revealed a significant decrease in the $\beta$ of maladaptive perfectionism and psychological distress with the implementation of trait emotional intelligence as a mediator $(z=5.78, p<.001)$ (see Figure 2). 


\section{Discussion}

The purpose of this research was to investigate the relationship between maladaptive perfectionism and psychological distress in university students. The study also aimed to investigate resilience and trait emotional intelligence as possible mediating factors of maladaptive perfectionism and psychological distress. The first hypothesis was met, showing a significant positive correlation between maladaptive perfectionism and psychological distress. The second hypothesis was also met, identifying maladaptive perfectionism and (negatively) resilience and trait emotional intelligence as significant predictors of psychological distress. Hypothesis three and four were partially met, with resilience and trait emotional intelligence being identified as partial mediators of maladaptive perfectionism and psychological distress.

The results of this research were consistent with previous literature and contribute to the ongoing investigation of maladaptive perfectionism in university students. Whilst psychological distress is a common topic in university mental health literature, treatment and interventions focused more directly on maladaptive perfectionism may be more client-centred and effective for students with perfectionistic tendencies (Radhu et al., 2012). Consistent with previous findings, the results of this study identified resilience and trait emotional intelligence as important variable to consider for the prevention or control of perfectionism in students (cf., Flett \& Hewitt, 2014; Klibert et al., 2014). However, both of these constructs in relation to maladaptive perfectionism are under researched. It is recommended future studies investigate building resilience and trait emotional intelligence in conjunction with treatment for university distress. Universities could investigate the implementation of resilience and trait emotional intelligence interventions to reduce academic distress related to perfectionism.

Whilst this research contributed to current available literature, there are a number of limitations with the study. Firstly, traits of perfectionism tend to be seen as socially desirable in academic settings such as striving for goals and persistent improvement (Stoeber \& Hotham, 2013). Not implementing a social desirability scale into the study may have hindered the true nature of the variable, with participants potentially overstating levels of perfectionism and increasing the possibility of a Type I error (Stoeber \& Hotham, 2013). Secondly, the demographic sample sizes were significantly different, reducing the generalisability of the study and threatening the external validity of the results. Future studies could incorporate a social desirability scale when testing perfectionism on university students and aim for a more representable sample. Thirdly, by providing participants with definitions regarding the differences in distress and eustress, it is possible that the sample may have been clued to the studies purpose and biased the responses.

In response to the increasing prevalence of psychological distress and maladaptive perfectionism within the university student community, the current research aimed to expand upon the literature and identify possible constructs that mediate the relationship between psychological distress and maladaptive perfectionism. Results from the current study supported the hypothesis that maladaptive perfectionism positively correlates with a more general form of psychological distress in university students. Supporting hypothesis two, the combination of high maladaptive perfectionism and low levels of resilience and trait emotional intelligence significantly predicted psychological distress in the sample. Hypothesis three and four were partially supported, with resilience and trait emotional intelligence partially but not fully mediating the relationship between maladaptive perfectionism and psychological distress. Future research investigating these constructs may also want to utilise an experimental and longitudinal study design to determine the causative relationship between maladaptive perfectionism and psychological distress.

\section{References}

Aldea, M. A., \& Rice, K. G. (2006). The role of emotional dysregulation in perfectionism and psychological distress. Journal of Counseling Psychology, 53, 498-510. https://doi.org/10.1037/0022-0167.53.4.498

Antony, M. M., Purdon, C. L., Huta, V., \& Swinson, R. P. (1998). Dimensions of perfectionism across anxiety disorders. Behaviour $\quad$ Research and 1143-1154. https://doi.org/10.1016/S0005-7967(98)00083-7

Armstrong, A. R., Galligan, R. F., \& Critchley, C. R. (2011). Emotional intelligence and psychological resilience to negative life events. Personality and Individual Differences, 51, 331-336. https://doi.org/10.1016/j.paid.2011.03.025

Baron, R. M., \& Kenny, D. A. (1986). The moderator-mediator variable distinction in social psychological research: Conceptual, strategic, and statistical considerations. Journal of Personality and Social Psychology, 51, 1173-1182. https://doi.org/10.1037/0022-3514.51.6.1173 
Blankstein, K. R., \& Lumley, C. H. (2008). Multidimensional perfectionism and ruminative brooding in current dysphoria, anxiety, worry, and anger. Journal of Rational-Emotive \& Cognitive-Behaviour Therapy, 26, 168-193. https://doi.org/10.1007/s10942-007-0068-z

Blatt, S. J. (1995). The destructiveness of perfectionism: Implications for the treatment of depression. American Psychologist, 50, 1003-1020. https://doi.org/10.1037/0003-066X.50.12.1003

Block, J., \& Kremen, A. M. (1996). IQ and ego-resiliency: Conceptual and empirical connections and separateness. Journal of Personality and Social Psychology, 70, 349-361. https://doi.org/10.1037/0022-3514.70.2.349

Brown, T. A., Chorpita, B. F., Korotitsch, W., \& Barlow, D. H. (1997). Psychometric properties of the Depression Anxiety Stress Scale (DASS) in clinical samples. Behaviour Research and Therapy, 35, 79-89. https://doi.org/10.1016/S0005-7967(96)00068-X

Chang, Y. (2012). The relationship between maladaptive perfectionism with burnout: Testing mediating effect of emotion-focused coping. Personality and Individual Differences, 53, 635-639. https://doi.org/10.1016/j.paid.2012.05.002

Chow, B. W., Chiu, M. M., \& Wong, S. W. (2011). Emotional intelligence, social problem-solving and psychological distress: A study of Chinese undergraduate students. Journal of Applied Social Psychology, 41, 1958-1980. https://doi.org/10.1111/j.1559-1816.2011.00787.x

Christopoulos, M., \& Hicks, R. E. (2008). Occupational stress, perfectionism and depression among university students. In S. Boag (Ed.), Personality down under: Perspectives from Australia (pp. 201-210). Brisbane, QLD: Australian Academic Stress.

Connor, K. M., \& Davidson, J. R. T. (2003). Development of a new resilience scale: The Connor-Davidson resilience scale (CD-RISC). Depression and Anxiety, 18, 76-82. https://doi.org/10.1002/da.10113

Constantin, K., Pope, C. J., Miedema, V. C., Penney, A. M., Tett, R. P., \& Mazmanian, D. (2016). Trait emotional intelligence and emotional distress: A closer look. Personality and Individual Differences, 101, 472-473. https://doi.org/10.1016/j.paid.2016.05.113

Cooper, A., \& Petrides, K. V. (2010). A psychometric analysis of the Trait Emotional Intelligence Questionnaire-Short Form (TEIQue-SF) using item response theory. Journal of Personality Assessment, 92, 449-457. https://doi.org/10.1080/00223891.2010.497426

Davidson, J. R. T., \& Connor, K. M. (2016). Connor-Davidson resilience scale (CD-RISC) manual (Unpublished manuscript).

Demos, E. V. (1989). Resiliency in infancy. In T. F. Dugan, \& R. Cole (Eds.). The child of our times: Studies in the development of resiliency (pp. 3-22). Philadelphia, PA: Brunner/Mazel.

Egan, S. J., Wade, T. D., \& Shafran, R. (2011). Perfectionism as a transdiagnostic process: A clinical review. Clinical Psychology Review, 31, 203-212. https://doi.org/10.1016/j.cpr.2010.04.009

Eisenberg, D., Gollust, S. E., Goldberstein, E., \& Hefer, J. L. (2007). Prevalence and correlates of depression, anxiety, and suicidality among university students. American Journal of Orthopsychiatry, 77, 534-542. https://doi.org/10.1037/0002-9432.77.4.534

Enns, M. W., \& Cox, B. J. (2002). The nature and assessment of perfectionism: A critical analysis. In G. L. Flett, \& P. L. Hewitt (Eds.), Perfectionism: Theory, research and treatment (pp. 33-62). Washing, DC: American Psychological Association. https://doi.org/10.1037/10458-002

Fernandez, R., Salamonson, Y., \& Griffiths, R. (2012). Emotional intelligence as a predictor of academic performance in first-year accelerated graduate entry nursing students. Journal of Clinical Nursing, 21, 23-34. https://doi.org/10.1111/j.1365-2702.2012.04199.x

Flett, G., \& Hewitt, P. (2014). A proposed framework for preventing perfectionism and promoting resilience and mental health among vulnerable children and adolescents. Psychology in the Schools, 51, 899-912. https://doi.org/10.1002/pits.21792

Flett, G., Madorsky, D., Hewitt, P., \& Heisel, M. (2002). Perfectionism cognitions, rumination, and psychological distress. Journal of Rational-Emotive and Cognitive-Behaviour Therapy, 20, 33-47. https://doi.org/10.1023/A:1015128904007 
Forushani, N. Z., \& Besharat, M. A. (2011). Relation between emotional intelligence and perceived stress among female students. Procedia: Social and Behavioural Science, 30, 1109-1112. https://doi.org/10.1016/j.sbspro.2011.10.216

Frost, R. O., Heimberg, R. G., Holt, C. S., Mattia, J. I., \& Neubauer, A. L. (1993). A comparison of two measures of perfectionism. Personality and Individual Differences, 14, 119-126. https://doi.org/10.1016/0191-8869(93)90181-2

Frost, R. O., Marten, P., Lahart, C., \& Rosenblate, R. (1990). The dimensions of perfectionism. Cognitive Therapy and Research, 14, 449-468. https://doi.org/10.1007/BF01172967

Gnilka, P. B., Ashby, J. S., \& Noble, C. M. (2013). Adaptive and maladaptive perfectionism as mediators of adult attachment styles and depression, hopelessness, and life satisfaction. Journal of Counseling and Development, 91, 78-86. https://doi.org/10.1002/j.1556-6676.2013.00074.x

Haefell, G. J., \& Vargas, I. (2011). Resilience to depressive symptoms: The buffering effects of enhancing cognitive style and positive life events. Journal of Behaviour Therapy and Experimental Psychiatry, 42, 13-18. https://doi.org/10.1016/j.jbtep.2010.09.003

Hewitt, P. L., Flett, G. L., \& Ediger, E. (1996). Perfectionism and depression: A longitudinal assessment of a specific vulnerability hypothesis. Journal of Abnormal Psychology, 105, 276-280. https://doi.org/10.1037/0021-843X.105.2.276

Jackson, M., \& Hicks, R.E. (2008). Low emotional intelligence and maladaptive perfectionism. In S. Boag (Ed.), Personality down under: Perspectives from Australia (pp. 189-200). New York, NY: Nova Science Publishers.

James, K., Verplanken, B., \& Rimes, K. A. (2015). Self-criticism as a mediator in the relationship between unhealthy perfectionism and distress. Personality and Individual Differences, 79, 123-128. https://doi.org/10.1016/j.paid.2015.01.030

Klibert, J., Lamis, D. A., Collins, W., Smalley, K. B., Warren, J. C., Yancey, T. C., \& Winterowd, C. (2014). Resilience mediates the relations between perfectionism and college student distress. Journal of Counseling and Development, 92, 75-82. https://doi.org/10.1002/j.1556-6676.2014.00132.x

Klohnen, E. C. (1996). Conceptual analysis and measurement of the construct of ego-resiliency. Journal of Personal and Social Psychology, 70, 1067-1079. https://doi.org/10.1037/0022-3514.70.5.1067

Krumpfer, K. L. (1999). Factors and processes contributing to resilience: The resilience framework. In M. D. Glantz, \& J. L. Johnson (Eds.), Resilience and development: Positive life adaptions (pp. 179-224). New York, NY: Kluwer Academic/Plenum Publishers.

Laborde, S., Allen, M. S., \& Gullién, F. (2016). Construct and concurrent validity of the short- and long-form versions of the trait emotional intelligence questionnaire. Personality and Individual Differences, 101, 232-235. https://doi.org/10.1016/j.paid.2016.06.009

Lovibond, P. F., \& Lovibond, S. H. (1995). The structure of negative emotional states: Comparison of the depression anxiety stress scales (DASS) with the Beck depression and anxiety inventories. Behaviour Research and Therapy, 33, 335-343. https://doi.org/10.1016/0005-7967(94)00075-U

Lynd-Stevenson, R. M., \& Hearne, C. (1999). Perfectionism and depressive affect: The pros and cons of being a $\begin{array}{llll}\text { perfectionist. Personality and Individual Differences, 26, 549-562. } & \text { an }\end{array}$ https://doi.org/10.1016/S0191-8869(98)00170-6

Magnano, P., Craparo, G., \& Paolillo, A. (2016). Resilience and emotional intelligence: The role of achievement motivation. International Journal of Psychological Research, 9, 9-20. https://doi.org/10.21500/20112084.2096

Mcgahuey, C. A., Gelenberg, A. J., Laukes, C. A., Moreno, F. A., Delgado, P. L., McKnight, K. M., \& Manber, R. (2000). The Arizona Sexual Experience Scale (ASEX): Reliability and validity. Journal of Sex and Marital Therapy, 26, 25-40. https://doi.org/10.1080/009262300278623

Mead, M. R., \& Hicks, R. E. (2010). Psychopathology and perfectionism among Australian university students. In R. E. Hicks (Ed.), Personality and individual differences: Current directions (pp. 248-257). Brisbane, QLD: Australian Academic Press. 
Park, H., Heppner, P., \& Lee, D. (2010). Maladaptive coping and self-esteem as mediators between perfectionism and psychological distress. Personality and Individual Differences, 48, 469-474. https://doi.org/10.1016/j.paid.2009.11.024

Petrides, K. V. (2009). Technical manual for the Trait Emotional Intelligence Questionnaire (TEIQue). London, UK: London Psychometric Laboratory.

Petrides, K., \& Furnham, A. (2001). Trait emotional intelligence: Psychometric investigation with reference to establish trait taxonomies. European Journal of Personality, 15, 425-448. https://doi.org/10.1002/per.416

Petrides, K., Pérez-González, J., \& Furnham, A. (2007). On the criterion and incremental validity of trait emotional intelligence. Cognition and Emotion, 21, 26-55. https://doi.org/10.1080/02699930601038912

Preacher, K. J. (2017). Calculation for the Sobel test: An interactive calculation tool for mediation tests. Retrieved from http://quantpsy.org/sobel/sobel.htm

Radhu, N., Daskalakis, Z. J., Guglietti, C. L., Farzan, F., Barr, M. S., Arpin-Cribbie, C. A., Fitzherald, P. B., \& Ritvo, P. (2012). Cognitive behavioural therapy-related increases in cortical inhibition in problematic perfectionists. Brain Stimulation, 5, 44-54. https://doi.org/10.1016/j.brs.2011.01.006

Rice, K. G., Vergara, D. T., \& Aldea, M. A. (2006). Cognitive-affective mediators of perfectionism and college student adjustment. Personality and Individual Differences, 40, 463-473. https://doi.org/10.1016/j.paid.2005.05.011

Rice, K., Ray, M., Davis, D., DeBlaere, C., \& Ashby, J. (2015). Perfectionism and longitudinal patterns of stress for stem majors: Implications for academic performance. Journal of Counseling Psychology, 62, 718-731. https://doi.org/10.1037/cou0000097

Sassaroli, S., Lauro, L. J. R., Ruggiero, G. M., Mauri, M. C., Vinai, P., \& Frost, R. (2008). Perfectionism in depression, obsessive-compulsive disorder and eating disorders. Behaviour Research and Therapy, 46, 757-765. https://doi.org/10.1016/j.brat.2008.02.007

Shi, J., \& Wang, L. (2007). Validation of emotional intelligence scale in Chinese university student. Personality and Individual Differences, 43, 377-387. https://doi.org/10.1016/j.paid.2006.12.012

Slaney, R., Rice, K., \& Ashby, J. (2002). A programmatic approach to measuring perfectionism: The almost perfect scales. In G, Flett, \& P. L. Hewitt (Eds.), Perfectionism: Theory, research, and treatment (pp. 63-88). Washington, DC: American Psychological Association.

Smith, M. M., Saklofske, D. H., \& Nordstokke, D. W. (2014). The link between neuroticism and perfectionistic concerns: The mediating effect of trait emotional intelligence. Personality and Individual Differences, 61, 97-100. https://doi.org/10.1016/j.paid.2013.12.013

Stallman, H. M. (2010). Psychological distress in university students: A comparison with general population data. Australian Psychologist, 45, 249-257. https://doi.org/10.1080/00050067.2010.482109

Stoeber, J., \& Hotham, S. (2013). Perfectionism and social desirability: Students report increased perfectionism to create a positive impression. Personality and Individual Differences, 55, 626-629. https://doi.org/10.1016/j.paid.2013.04.023

Stoeber, J., \& Rambow, A. (2007). Perfectionism in adolescent school students: Relations with motivation, achievement, and well-being. Personality and Individual Differences, 42, 1379-1389. https://doi.org/10.1016/j.paid.2006.10.015

Tabachnick, B. G., \& Fidell, L. S. (2013). Using multivariate statistics (6th ed.). Boston, MA: Pearson.

Tugade, M. M., \& Fredrickson, B. L. (2004). Resilient individuals use positive emotions to bounce back from negative emotional experiences. Journal of Personality and Social Psychology, 86, 320-222. https://doi.org/10.1037/0022-3514.86.2.320

Wolin, S. J., \& Wolin, S. (1993). Bound and determined: Growing up resilient in a troubled family. New York, NY: Villard Press.

\section{Copyrights}

Copyright for this article is retained by the author(s), with first publication rights granted to the journal.

This is an open-access article distributed under the terms and conditions of the Creative Commons Attribution license (http://creativecommons.org/licenses/by/4.0/). 